\title{
Metal Salt and Non-Electrolyte Separation by Means of Dialysis through the Composite Membranes
}

\author{
Elena Butyrskaya*, Natalia Belyakova, Ludmila Nechaeva, Lubov Zolotaryova, \\ Vladimir Shaposhnik, Vladimir Selemenev \\ Department of Analytical Chemistry, Federal Institution for Higher Education "Voronezh State University, \\ Voronezh, Russian Federation \\ Email: "bev5105@yandex.ru
}

Received 3 April 2016; accepted 16 May 2016; published 19 May 2016

Copyright (C) 2016 by authors and Scientific Research Publishing Inc.

This work is licensed under the Creative Commons Attribution International License (CC BY). http://creativecommons.org/licenses/by/4.0/

c. (i) Open Access

\begin{abstract}
To separate salts of metals and non-electrolytes, the approach of dialysis through the composite membranes (CMs) is proposed. CM is a combination of cation and anion exchange areas. In the composite membrane, cations and anions are transferred through the respective exchange areas simultaneously without violation of macroscopic electro-neutrality. This provides a better transfer of salts than conventional ion exchange membranes (IEMs). The dialysis of the ethylene glycol aqueous salt solutions through the CMs was investigated. We have shown that the transport of salts through the composite membranes is more intensive (unlike IEM providing no transfer of salts from weakly mineralized aqueous solutions due to the Donnan exclusion) and the ethylene glycol transfer is not very significant, that is the basis of effective separation. The possibility to use of composite membranes for metal salt and other electrolyte separation is discussed.
\end{abstract}

\section{Keywords}

Membranes, Composite Membranes, Electrolytes, Non-Electrolytes, Separation, Sodium Chloride, Potassium Chloride, Ethylene Glycol

\section{Introduction}

The development of methods of separation and concentration of aqueous solutions of electrolytes and nonelectrolytes is the most important task of analytical chemistry. This task aims at improving the analytical properties

${ }^{*}$ Corresponding author.

How to cite this paper: Butyrskaya, E., Belyakova, N., Nechaeva, L., Zolotaryova, L., Shaposhnik, V. and Selemenev, V. (2016) Metal Salt and Non-Electrolyte Separation by Means of Dialysis through the Composite Membranes. American Journal of Analytical Chemistry, 7, 478-486. http://dx.doi.org/10.4236/ajac.2016.75045 
of the components of the mixtures and analytical control in various fields of industry, science and the environment. For this purpose, the chromatography, extraction, precipitation, distillation, and electrochemical methods are used. Economic expediency and environmental feasibility of the dialysis in comparison with the majority of these methods determines the relevance of this separation method.

An effective separation of the metal salts (electrolytes) and non-electrolytes is observed during the dialysis of their aqueous solutions through mosaic membranes (MM) [1] [2]. Mosaic membranes are most frequently synthesized as a set of parallel anion exchange areas (AEAs) and cation exchange areas (CEAs) [3]. Anions and cations are transported through the membrane by the parallel areas (anions are transported by the AEAs, and cations are transported by CEAs) without a violation of macroscopicelectro-neutrality [4] [5]. However, the synthesis of MM with parallel areas is rather complicated, so they are not widely used in industry [5]. In Russian Federation (OOO”IP” Shchekinoazot”) the composite membranes (CMs) are synthesized [6]. They are a kind of MM, but they are easier to manufacture, due to the lack of parallelism of cation and anion exchange areas.

Efficient separation of salts and non-electrolytes using MM is due to their high-permeability for salts and their low permeability to nonelectrolytes [1]-[6]. The latter is a result of the special synthesis conditions having small pores in the MM [5]. Knowing that the transport of electrolytes by dialysis through a MM is more efficient compared to the transport through the traditional Ion Exchange Membrane (IEM) [4] [7] [8]. Justification of this phenomenon is given in the works of Kedem, Katchalsky et al. [9]. It is based on the methodology of nonequilibrium thermodynamics. The authors of [9] have obtained an analytic expression of salt permeability through the MM, containing additional compared to the IEM term. The magnitude of one is about 100 times larger of IEM permeability. The authors of [1] believe that dialysis with a composite membranes due to its efficient transfer of electrolytes is alternative electrical dialysis because energy costs are reduced.

The development of the methods for separation and concentration is also important to enhance the environmental safety of natural resources regarding the wastewater of different processes. For example, one of the problems of production factories using ethylene glycol is the presence of wastewater containing the EG mixed with mineral salts. Their wasting without the pre-treatment is unacceptable, because the ethylene glycol is a toxic substance. There are various methods of neutralization, for example, ozonation, and electrical treatment. However, ethylene glycol is a valuable organic substance, so it makes sense to obtain it from the wastewater for reuse.

In [10]-[12] authors have proposed a method to separation of weakly mineralized water-glycol solutions by means of dialysis with IEMs to separate efficiently EG and alkali metal salts. In these works, to exclude the ion exchange, membranes were in the ion form of one of the ions of separated from EG salt. Due to the occurrence of the Donnan exclusion, transfer of small concentrations of electrolyte through the membrane in these cases is precluded, while EG transfer takes place.

In this paper, we have studied an example of separation of electrolyte and non-electrolyte by dialysis through the composite membranes of aqueous solutions of alkali metal salts and ethylene glycol. The use of the combined membranes for the separation of other non-electrolytes and metal salts is considered.

\section{Experimental Section}

\subsection{Materials and Reactants}

The AK-30, AK-45, and AK-80 composite membranes (OOO "IP" Shchekinoazot") were used in experiment. The AK composite membranes are based on a mixture of ground cation exchange and anion exchange materials pressed with a binder material. Anion AV-17-2P and cation KU-2 industrial ion exchange resins are conditioned and dried. Components (cation exchange material-10 - 80 mass\%, anion exchange material -80 - 10 mass \%, a polymeric binder - the rest) are ground and mixed in a mixer [6]. The resulting mixture is further homogenized and melted, providing smaller CM pores as compared to the conventional ion-exchange membrane. Then the sample is rolled and passed to a press. The pressure of $250 \mathrm{~atm}$ and the temperature of $140^{\circ} \mathrm{C}$ cause the formation of a combined membrane sheet and its reinforcement. The resulting membranes have a fine hardness, improved physicochemical properties, and reversibility after the intensive drying. Combined composite membranes are designated as AK- $\mathrm{N}$, where $\mathrm{N}$ indicates the percentage of component in anion ion-exchange membrane material. If the cation area of the membrane is in the form of $\mathrm{Na}$ and ion-exchange-valued part is in the form of $\mathrm{Cl}$, then it is say that the CM is in the form of $\mathrm{NaCl}$.

To prepare the water-glycol solutions, the chemically pure ethylene glycol was used from Komponentreactiv 
Ltd (Russia). To prepare the aqueous solutions of alkali metal salts, chemically pure sodium and potassium chlorides are used from Sigma Aldrich Ltd (Russia).

\subsection{Dialysis Details}

The dialysis of mineral salts, ethylene glycol, and ethylene glycol containing mineral salt additives was studied in a thermostated $\left(25^{\circ} \mathrm{C}\right)$ two-section glass cell. The flow initial section and closed receiving section of cell were divided by one of the AK-30, AK-45, and AK-80 type CMs.

Test solutions of different concentrations preheated to $25^{\circ} \mathrm{C}$ were fed into the flow initial section. The distilled water at $25^{\circ} \mathrm{C}$ was placed in receiver section. The feed rate in all cases was $2.9 \mathrm{ml} / \mathrm{min}$.

\subsubsection{Transfer of Alkali Metal Salts through the Combined Membrane}

The dialysis of $\mathrm{NaCl}(\mathrm{KCl})$ solutions with concentrations $0.001 \mathrm{~mol} / \mathrm{l} ; 0.01 \mathrm{~mol} / \mathrm{l} ; 0.1 \mathrm{~mol} / \mathrm{l}$ was studied. The entire solution from the receiving section was decanted every 15, 30, 60,120, 180 minutes and then distilled water was placed in this section. The decanted solutions were analyzed by flame photometry method. For $\mathrm{KCl}$, the receiver section was monitored additionally after 240 minutes of dialysis. The slower transfer of $\mathrm{KCl}$ versus $\mathrm{NaCl}$ was detected. According to the electrical neutrality condition, the concentration of $\mathrm{Na}+(\mathrm{K}+)$ in the receiver section is equal to the concentration of salts. To preclude of ion-exchange when studying the $\mathrm{NaCl}$ aqueous solutions, the composite membrane was in $\mathrm{NaCl}$ form. It was in $\mathrm{KCl}$ form for the study of the $\mathrm{KCl}$ aqueous solution.

\subsubsection{Glycol Transfer through the Composite Membrane}

$0.1 \mathrm{M}(0.01 \mathrm{M}) \mathrm{EG}$ aqueous solutions were fed to the initial section. CMs were alternately combined in the forms of $\mathrm{KCl}$ and $\mathrm{NaCl}$. The concentration of ethylene glycol in the receiver section was defined by redox titration. Determination of ethylene glycol based on its oxidation with excess potassium dichromate in the presence of concentrated sulfuric acid.

Equation of the reaction:

$$
3 \mathrm{HOCH}_{2} \mathrm{CH}_{2} \mathrm{OH}+5 \mathrm{~K}_{2} \mathrm{Cr}_{2} \mathrm{O}_{7}+20 \mathrm{H}_{2} \mathrm{SO}_{4}=5 \mathrm{~K}_{2} \mathrm{SO}_{4}+5 \mathrm{Cr}_{2}\left(\mathrm{SO}_{4}\right)_{3}+29 \mathrm{H}_{2} \mathrm{O}+6 \mathrm{CO}_{2} \text {. }
$$

Then, we determined the content of the excess potassium dichromate iodometrically:

$$
\mathrm{K}_{2} \mathrm{Cr}_{2} \mathrm{O}_{7}+6 \mathrm{KJ}+\mathrm{H}_{2} \mathrm{SO}_{4}+12 \mathrm{HCl}=6 \mathrm{KCl}+\mathrm{K}_{2} \mathrm{SO}_{4}+2 \mathrm{CrCl}_{3}+3 \mathrm{~J}_{2}+7 \mathrm{H}_{2} \mathrm{O}
$$

The obtained iodine is titrated with sodium thiosulfate solution:

$$
\mathrm{J}_{2}+\mathrm{Na}_{2} \mathrm{~S}_{2} \mathrm{O}_{3}=2 \mathrm{NaJ}+\mathrm{Na}_{2} \mathrm{~S}_{4} \mathrm{O}_{6}
$$

\subsubsection{Dialysis of Ethylene Glycol Water-Salt Solution through a Composite Membrane}

Aqueous EG salt solutions shown in Table 1 were fed into the initial section.

The dialysis of these solutions through the composite membranes in $\mathrm{NaCl}$ and $\mathrm{KCl}$ forms was investigated. Determination of $\mathrm{Na}^{+}\left(\mathrm{K}^{+}\right)$cations in the receiver section was done by flame photometry method. Determination of ethylene glycol was done by redox titration.

\section{Results and Discussion}

\subsection{Transfer of Alkali Metal Salts through the Composite Membrane}

Table 2 shows the receiver section electrolyte concentration versus initial section concentration (\%) with different




dialysis times for the $\mathrm{NaCl}(\mathrm{KCl})$ transport through $\mathrm{AK}-30$, AK-45, AK-80 composite membranes in $\mathrm{NaCl}(\mathrm{KCl})$ form and through MK-40 cation exchange membrane in Na form. It was found that within 15 minutes of the electrolyte occurs in the receiver section of any type of CM. Electrolyte (small concentrations) don't pass the IEM MK-40 due to the Donnan exclusion.

Due to the choice of the ionic form of composite membrane (in the $\mathrm{NaCl}$ form) and electrolyte solution $(\mathrm{NaCl})$, there is no ion exchange. The electrolyte transport goes by means of molecular diffusion. This process differs from the diffusion of non-exchange sorbed electrolyte in conventional ion-exchange membrane. Namely, in Sollner article [4], it is shown that anions are transferred through AEAs and cations are transferred through CEAs simultaneously in CMs without electrical neutrality violation. Thus, the molecular diffusion is the resulting CM transfer process. However, in case of conventional ion-exchange membrane, non-exchange sorbed electrolyte is absorbed by either only cation exchange or only anion exchange membrane (subject to the used membrane type). In the composite membranes, both cation and anion exchange areas participate in transfer with both cations and anions transmitting through them. Therefore, molecular diffusion for non-exchange sorbed electrolyte is slower through IEM than through CM [4] [7] [8]. In addition, the experiment shows that salt from aqueous solutions at low concentrations pass CM effectively. That is not the case for the ion-exchange membranes due to the Donnan exclusion. We can explain it as follows: neither AEA nor CEA transmit co-ions due to the Donnan exclusion (anions are co-ions to the cation exchange membrane and vice versa). In composite membranes, AEA transmits anions and repels cations and CEA transports cations and repels anions. Thus, CM can transmit both cations and anions even with a smaller salt concentration.

Moreover, the experiment has shown that the CM permeability is better for smaller initial salt concentrations. For AK-45 CM and initial $\mathrm{NaCl}$ concentration of $0.001 \mathrm{~mol} / \mathrm{l}$ (3 hour dialysis) receiver section concentration is $94 \%$ of the initial concentration. For $\mathrm{C}_{0}=0.01 \mathrm{~mol} / \mathrm{l}$ it is $87 \%$, and for $\mathrm{C}_{0}=0.1 \mathrm{~mol} / \mathrm{l}$ it is just $35.6 \%$. This is apparently due to the structural characteristics of the membrane. Indeed, in the simplest case, a single composite membrane is a set of contiguous staggered anion and cation areas (Figure 1).

In the composite membrane, there are "bottlenecks" where opposite type membranes are contacted (shown as circles on the Figure 1). This limits the maximum permeability of each ion type through CM, due to small contact area. It leads to decrease in membrane permeability when the concentration of electrolyte in initial section is increasing.

Figures 2-4 show the $\mathrm{NaCl}$ and $\mathrm{KCl}$ receiver section concentrations versus dialysis time for $\mathrm{AK}-30$, AK-45 and AK-80 composite membranes and different initial concentration in the initial section.

Figures 2-4 are non-linear graphs with inflections. This form doesn't allow describing the diffusion constant flux and constant permeability coefficient. In some cases, $\mathrm{C}(\mathrm{t})$ graphs for composite membranes have 3 parts. First and third parts have a faster salt concentration increase in the receiver section with the increased dialysis time. The second part shows as lower increase of the receiver section concentration (sometimes the graph is almost flat). This has two apparent reasons. The first reason is a curvilinear electrolyte transport path. The second is the dead-end paths providing no access to the receiver section.

Table 2 and Figures 2-4 show that the AK-45 membrane is the most effective to $\mathrm{NaCl}$ and $\mathrm{KCl}$ transfer for all the considered concentrations. This is due to 45:55 ration of cation and anion exchange areas in this membrane. There are almost identical transfer areas for cations and anions. For AK-50 membrane, 1:1 solution of

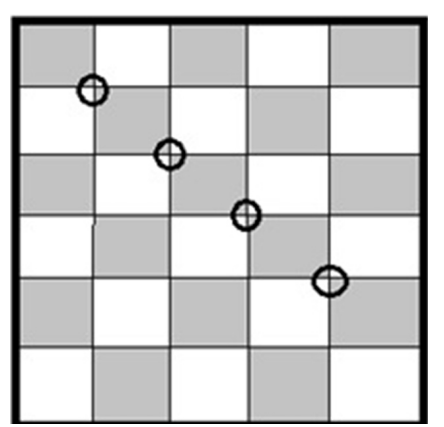

Figure 1. The simplest CM model. Grey squares depictcation exchange membranes (cation transport area), and the white squares depictanion exchange membranes (anion transport area), circles are "bottleneck" areas where the ion exchange membranes abut. 


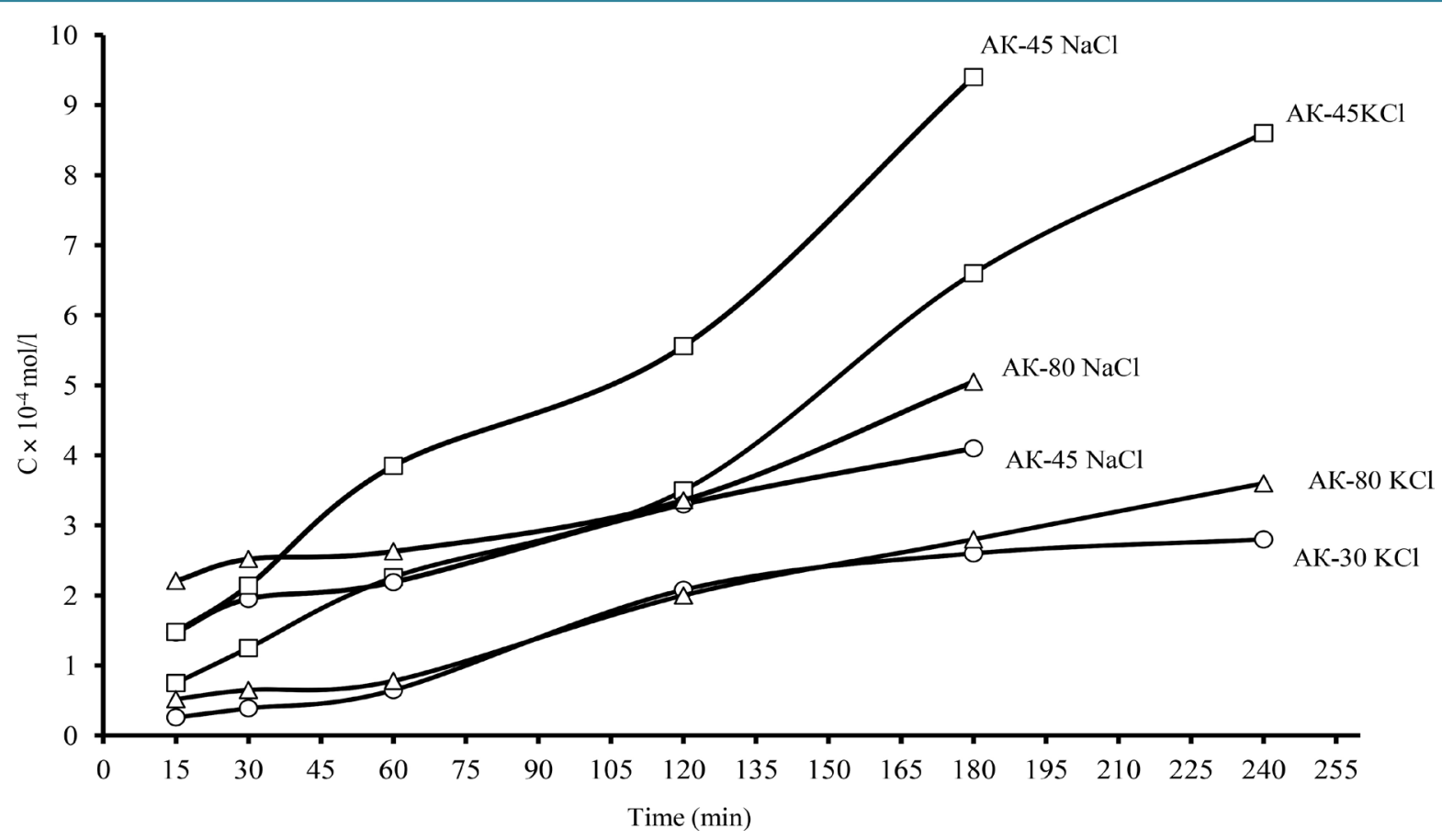

Figure 2. Dialysis time dependence of $\mathrm{NaCl}(\mathrm{KCl})$ initial section concentration for AK-30, AK-45, and AK-80 membranes in $\mathrm{NaCl}(\mathrm{KCl})$ forms $\left(\mathrm{C}_{0}=0.001 \mathrm{~mol} / \mathrm{l}\right)$.

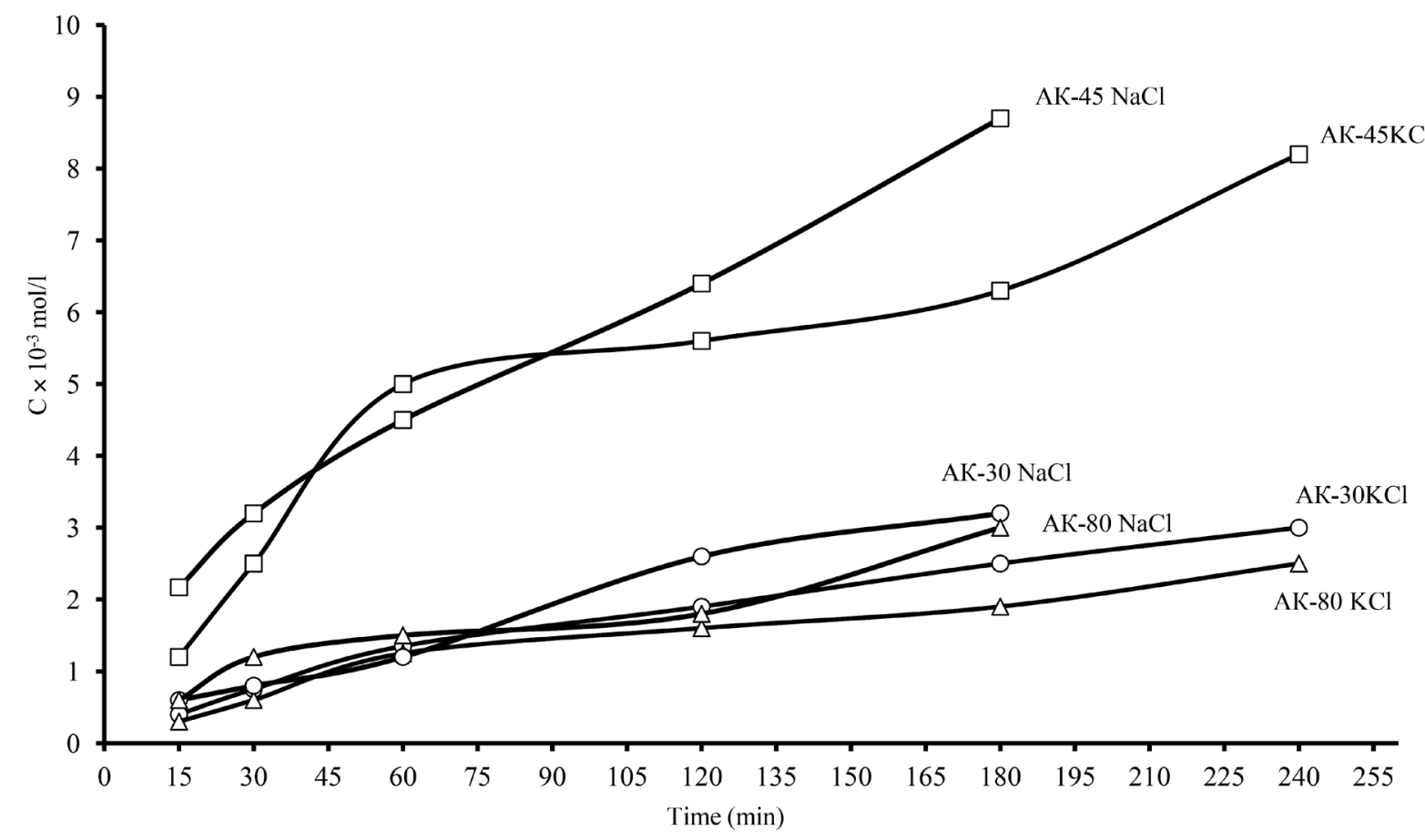

Figure 3. Dialysis time dependence of $\mathrm{NaCl}(\mathrm{KCl})$ end section concentration for $\mathrm{AK}-30, \mathrm{AK}-45$, and $\mathrm{AK}-80$ membranes in $\mathrm{NaCl}(\mathrm{KCl})$ forms $\left(\mathrm{C}_{0}=0.01 \mathrm{~mol} / \mathrm{l}\right)$.

electrolite should have the best transport properties. For AK-30 membrane with 30\% of AEA and 70\% of CEA, electrolyte transfer is slighter, than forAK-45. Such a transport is done by molecular diffusion (electrical neutrality condition). AEA is 2.3 times smaller than CEA. Thus, AEA limits the electrolyte transfer.

Regarding Table 2 and Figures 2-4, the potassium chloride passes the membrane slower than sodium chloride. 


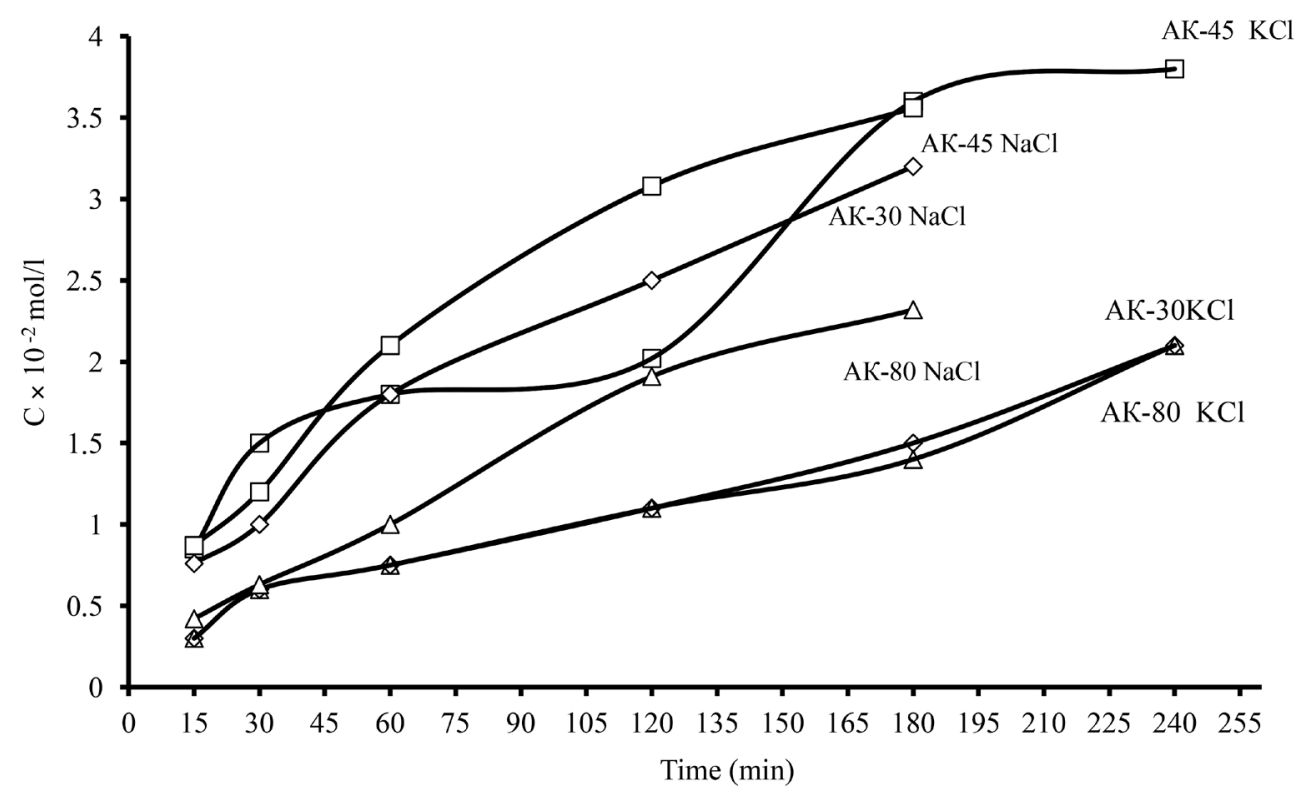

Figure 4. Dialysis time dependence of $\mathrm{NaCl}(\mathrm{KCl})$ end section concentration for AK-30, AK-45, and AK-80 membranes in $\mathrm{NaCl}(\mathrm{KCl})$ forms $\left(\mathrm{C}_{0}=0.1 \mathrm{~mol} / \mathrm{l}\right)$.



Figure 5. Time dependence of EG end section concentration for AK-45 membrane in $\mathrm{NaCl}$ form (graph 1) and in $\mathrm{KCl}$ form (graph 2). Initial section EG concentration is $0.1 \mathrm{~mol} / \mathrm{l}$.

Thus, due to the difference of IEM and CM surface properties, transport properties also differ. In general, transport of low salt concentration from aqueous solution is rather intensive through CMs.

\subsection{Transferring of Ethylene Glycol through a Composite Membrane}

Figure 5 shows the time dependence of receiver section EG concentration (initial concentration is $0.1 \mathrm{~mol} / \mathrm{l}$ ) for AK-45 transfer.

Following the figure, EG barely passes $\mathrm{KCl}$ and $\mathrm{NaCl}$ form membranes. EG transport through $\mathrm{KCl}$ form AK-45 membrane is $4.3 \%$ for 4 hours and $2.5 \%$ for 3 hours for $\mathrm{NaCl}$ form membrane. This results from insufficient CM pore size. The pores are too small to transmit even as little molecule as EG. During this time, about $90 \%$ of alkali metal salts pass the membrane from their aqueous solutions having $0.01 \mathrm{~mol} / \mathrm{l}$ and $0.001 \mathrm{~mol} / \mathrm{l}$ concentrations (Table 2). This allows using AK-45 composite membrane to separate EG from alkali metal salts. In this work, we has also been investigated transfer of 0.01 M EG through composite membranes. During 3 hours, less than $2 \%$ of EG passes the membrane. Further research is carried out with a concentration of EG in the initial section of $0.1 \mathrm{~mol} / \mathrm{l}$. 


\subsection{Dialysis of Aqueous Salt EG Solution through the Composite Membrane}

Separation of salt and EG by dialysis through IEM [10]-[12] is based on Donnan exclusion of electrolyte out of the membrane and the transfer of EG through IEM. In case of CM, the separation is based on the intensitive transfer of electrolyte through CM and a small transfer of ethylene glycol EG through one.

EG transfer from both its aqueous salt solution and water solution through the composite membrane is slight. Adding salt very slightly affects EG transfer, which is $4.3 \%$ for 4 hours forAK- 45 in $\mathrm{KCl}$ form membrane and $2.5 \%$ for 3 hours in $\mathrm{NaCl}$ form membrane.

The experiment also shows that added EG does not affect the transport of aqueous alkali metal. Namely, the transfer through composite membrane $\mathrm{AK}-45$ is $94 \% \mathrm{NaCl}\left(3\right.$ hour dialysis, $\left.\mathrm{C}_{0}=0.001 \mathrm{~mol} / \mathrm{l}\right)$ and $84 \% \mathrm{KCl}(4$ hour dialysis, $\mathrm{C}_{0}=0.001 \mathrm{~mol} / \mathrm{l}$ ) from aqueous salt EG solution. Similarly for $\mathrm{C}_{0}=0.01 \mathrm{~mol} / \mathrm{l}$, this transport through the membrane is $87 \% \mathrm{NaCl}$ (3 hour dialysis) and $76 \% \mathrm{KCl}$ (4 hour dialysis). These results are almost identical to the results in the Table 2, which presents transport characteristics of CM alkali metal salt aqueous solutions. For electrolyte concentration of $0.1 \mathrm{~mol} / \mathrm{l}$, the presence of EG in the solution slightly improves the electrolyte transfer compared to those in the salt solution.

The maximum relative standard deviation in all cases was $4.5 \%$.

To evaluate the efficiency of $E G$ separation from alkali metal salts, separation factors of $E G$ and salts are calculated using the following formula:

$$
\alpha=\frac{C_{M e^{+}} / C_{E G}}{C_{M e^{+}}^{0} / C_{E G}^{0}},
$$

where $C_{M e^{+}}\left(C_{E G}\right)$ is salt $(E G)$ concentration in the receiver section, while $C_{\mathrm{Me}^{+}}^{0}\left(C_{E G}^{0}\right)$ is the concentration of salt and $E G$ in the initial solution.

The separation factor of $E G$ and $\mathrm{NaCl}$ for 3 hour long dialysis, and $E G$ and $\mathrm{KCl}$ for 4 hour long dialysis with AK-45 are represented in the Table 3.

Table 2. The ratio of receiver section salt concentration versus initial section salt concentration (\%) for different $\mathrm{NaCl}, \mathrm{KCl}$ CM dialysis time.

\begin{tabular}{|c|c|c|c|c|c|c|c|c|c|c|c|c|c|c|c|c|c|c|}
\hline \multirow{3}{*}{$\begin{array}{c}\text { Membrane, } \\
\text { type }\end{array}$} & \multicolumn{18}{|c|}{ The initial concentration of $\mathrm{NaCl}, \mathrm{KCl}\left(\mathrm{C}_{0}\right), \mathrm{mol} / \mathrm{l}$} \\
\hline & \multicolumn{6}{|c|}{$10^{-3}$} & \multicolumn{6}{|c|}{$10^{-2}$} & \multicolumn{6}{|c|}{$10^{-1}$} \\
\hline & $\begin{array}{c}15 \\
\min \end{array}$ & $\begin{array}{c}30 \\
\min \end{array}$ & $\begin{array}{c}60 \\
\min \end{array}$ & $\begin{array}{l}120 \\
\text { min }\end{array}$ & $\begin{array}{l}180 \\
\text { min }\end{array}$ & $\begin{array}{l}240 \\
\text { min }\end{array}$ & $\begin{array}{c}15 \\
\text { min }\end{array}$ & $\begin{array}{c}30 \\
\text { min }\end{array}$ & $\begin{array}{c}60 \\
\min \end{array}$ & $\begin{array}{l}120 \\
\min \end{array}$ & $\begin{array}{l}180 \\
\text { min }\end{array}$ & $\begin{array}{l}240 \\
\text { min }\end{array}$ & $\begin{array}{c}15 \\
\text { min }\end{array}$ & $\begin{array}{c}30 \\
\text { min }\end{array}$ & $\begin{array}{c}60 \\
\text { min }\end{array}$ & $\begin{array}{l}120 \\
\text { min }\end{array}$ & $\begin{array}{l}180 \\
\text { min }\end{array}$ & $\begin{array}{l}240 \\
\text { min }\end{array}$ \\
\hline \multicolumn{19}{|l|}{ AK-30 } \\
\hline $\mathrm{NaCl}$ & 15 & 20 & 21 & 33 & 41 & - & 6 & 8 & 12 & 26 & 32 & - & 8 & 11 & 17 & 24 & 32 & - \\
\hline $\mathrm{KCl}$ & 2.5 & 4 & 6.5 & 20 & 26 & 28 & 4 & 7.5 & 13.5 & 19 & 25 & 30 & 3 & 6 & 7.5 & 11 & 14 & 21 \\
\hline \multicolumn{19}{|l|}{ AK-45 } \\
\hline $\mathrm{NaCl}$ & 15 & 24 & 38.5 & 55.5 & 94 & - & 21 & 32 & 45 & 64 & 87 & - & 9 & 12 & 21 & 30 & 35 & - \\
\hline $\mathrm{KCl}$ & 7.5 & 12.5 & 22.5 & 30 & 66 & 86 & 12 & 25 & 50 & 56 & 63 & 82 & 8.5 & 15 & 18 & 20 & 36 & 39 \\
\hline \multicolumn{19}{|l|}{ AK-80 } \\
\hline $\mathrm{NaCl}$ & 22 & 25 & 26 & 33 & 50 & - & 6 & 12 & 15 & 18 & 30 & - & 4 & 6 & 10 & 19 & 23 & - \\
\hline $\mathrm{KCl}$ & 5 & 6.5 & 8 & 20 & 28 & 36 & 3 & 6 & 12.5 & 16 & 19 & 25 & 3 & 6 & 7.5 & 11 & 15 & 21 \\
\hline \multicolumn{19}{|l|}{ MK-40 } \\
\hline $\mathrm{Na}$ & 0 & 0 & 0.2 & 0.2 & 0.2 & - & 0 & 0.8 & 1.2 & 1.6 & 3 & - & 2 & 5 & 1 & 2 & 3 & - \\
\hline K & 0 & 0 & 0.2 & 0.2 & 0.2 & 0.2 & 0 & 0.4 & 0.4 & 0.8 & 0.8 & 0.8 & 1 & 2.5 & 3 & 3.5 & 3.5 & 4.5 \\
\hline
\end{tabular}

Table 3. Separation factors for $\mathrm{EG}$ and $\mathrm{NaCl}$ after 3-hour dialysis of $\mathrm{EG}$ and $\mathrm{KCl}$ after 4-hour dialysis through the AK-45 CM.

\begin{tabular}{ccc}
\hline Dialyzable solution & Separation factor \\
\hline $0.1 \mathrm{M} \mathrm{EG}+0.001 \mathrm{M} \mathrm{NaCl}$ & 38.4 \\
$0.1 \mathrm{M} \mathrm{EG}+0.01 \mathrm{M} \mathrm{NaCl}$ & 34.8 \\
$0.1 \mathrm{M} \mathrm{EG}+0.1 \mathrm{M} \mathrm{NaCl}$ & 23.9 \\
$0.1 \mathrm{M} \mathrm{EG}+0.001 \mathrm{M} \mathrm{KCl}$ & 9.5 \\
$0.1 \mathrm{M} \mathrm{EG}+0.01 \mathrm{M} \mathrm{KCl}$ & 16.9 \\
$0.1 \mathrm{M} \mathrm{EG}+0.1 \mathrm{M} \mathrm{KCl}$ & 12.9 \\
\hline
\end{tabular}


The large magnitude of separation factors indicates the effective dialysis separation of alkali metal salts and ethylene glycol through the combined membrane.

Despite the lack of parallelism and cationic ion-exchange areas for effective transfer CM low concentrations of electrolytes that can be used to concentrate various metal salts.

\section{Conclusion}

From this work and published data follows the low permeability of the CM for non-electrolytes (methanol, mannitol, urea, neutral amino acids) [1], sucrose [2] and a high its permeability for alkali metal salts [2], salts of doubly charged $\mathrm{CoCl}_{2}$ cations, $\mathrm{CuSO}_{4}, \mathrm{NiSO}_{4}, \mathrm{NiCl}_{2}$ [13]. Therefore it can be concluded that $\mathrm{CM}$ dialysis can be used to the concentration of metal cations in aqueous solutions and separate of organic substances and metal salts in aqueous mixtures.

\section{Acknowledgements}

This work is supported by the Federal Target Program, the Agreement No. 14.574.21.0112 of 21.10.2014, unique identificator RFMEFI57414X0112.

\section{References}

[1] Weinstein, J.N. and Caplan, S.R. (1970) Charge-Composite Membranes: Dialytic Separation of Electrolytes from Nonelectrolytes and Amino Acids. Science, 169, 296-298. http://dx.doi.org/10.1126/science.169.3942.296

[2] Fukuda, T., Yang, W., Yamauchi, A. (2003) KCl Transport Mechanism across Charged Composite Membrane in KCl-Sucrose Mixed System. Journal of Membrane Science, 212, 255-261. http://dx.doi.org/10.1016/S0376-7388(02)00506-9

[3] Higa, M. (2008) Charge Composite Membranes Prepared from Laminated Structures of PVA-Based Charged Layers: 1. Preparation and Transport Properties of Charged Composite Membranes. Journal of Membrane Science, 310, 466-473. http://dx.doi.org/10.1016/j.memsci.2007.11.024

[4] Neihof, R. and Sollner, K. (1955) A Quantitative Electrochemical Theory of the Electrolyte Permeability of Composite Membranes Composed of Selectively Anion-Permeable and Selectively Cation-Permeable Parts, and Its Experimental Verification. The Journal of General Physiology, 38, 613-622. http://dx.doi.org/10.1085/jgp.38.5.613

[5] Xu, T. (2005) Ion Exchange Membranes: State of Their Development and Perspective. Journal of Membrane Science, 263, 1-29. http://dx.doi.org/10.1016/j.memsci.2005.05.002

[6] Kulincov, P.I., Bobrinskaja, G.A., Agupova, M.V., Selemenev, V.F., Garshina, T.I., Sokol, B.A. and Savosh, Je.K. (2012) Kombinirovannye membrany s zaraneezadannoj izbiratel'noj selektivnost'ju (Combination Membrane Selectivity Predetermined Selective). Patent RF, No. 11524066.

[7] Weinstein, J.N., Misra, B.M., Kalif, D. and Caplan, S.R. (1973) Transport Properties of Charge-Composite Membranes II. Experimental Studies. Desalination, 12, 1-17. http://dx.doi.org/10.1016/S0011-9164(00)80171-X

[8] Yamauchi, A. (2012) Ion Transport through Diffusion Layer Controlled by Charge Composite Membrane. International Journal of Chemical Engineering, 2012, Article ID: 417179.

[9] Kedem, O. and Katchalsky, A. (1963) Permeability of Composite Membranes. Part 1. Electric Current, Volume Flow and Flow of Solute through Membranes. Transactions of the Faraday Society, 59, 1918-1942. http://dx.doi.org/10.1039/tf9635901918

[10] Rozhkova, M.V., Rozhkova, A.G. and Butyrskaya, E.V. (2007) Separation of Mineral Salts and Non-Electrolytes (Ethylene Glycol) Dialysis through the Ion-Exchange Membrane. hurnal analiticheskoj khimii (Journal of Analytical Chemistry), 62, 790-796.

[11] Rozhkova, M.V., Boev, Ju.Ju., Pershina, I.S., Reshetnikova, A.K. and Obrazcov, A.A. (2001) Evaluation of the Diffusion Constant of Ion-Exchange Membranes to Ethylene Glycol. Sorbcionnye i hromatograficheskie processy, 5, 885889.

[12] Butyrskaya, E.V., Belyakova, N.V., Rozhkova, M.V. and Nechaeva, L.S. (2012) Extraction of Ethylene Glycol from Aqueous Salt Solutions. Zhurnal fizicheskoj khimii (Russian Journal of Physical Chemistry A), 86, 1721-1725. http://dx.doi.org/10.1134/s0036024412110076

[13] Grzenia, D.L., Yamauchi, A. and Wickramasinghe, S.R. (2009)Electrolyte Dialysis Using Charge-Composite Membranes. Desalination and Water Treatment, 4, 306-310. http://dx.doi.org/10.5004/dwt.2009.481 


\section{Abbreviations}

AEA = Anion Exchange Area

CEA = Cation Exchange Area

$\mathrm{CM}=$ Composite Membrane

IEM = Ion Exchange Membrane

EG = Ethylene Glycol 